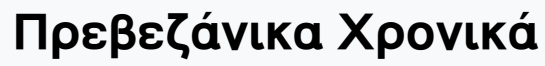

Ap. $47-48$ (2011)

ПPEBEZANIKA XPONIKA, 47-48 (2011)

П P E B E Z A N I K A

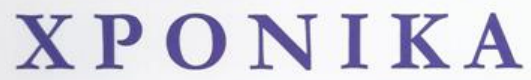

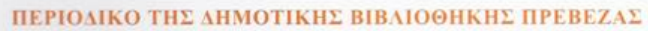

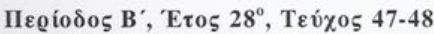

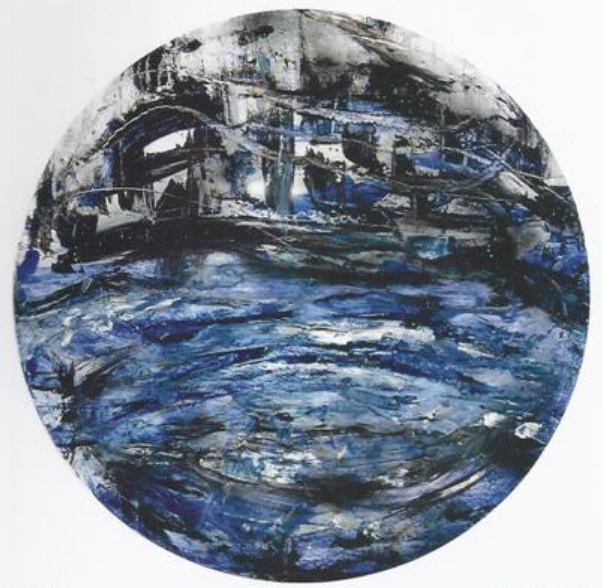

APXAIOAOTIA IITOPIA

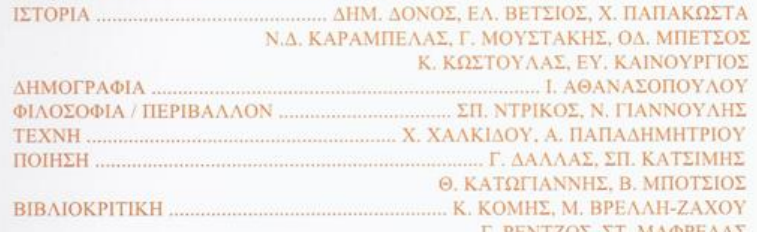

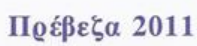

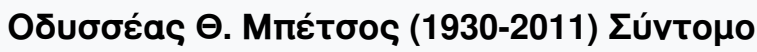

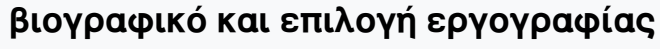

Michael Stork

doi: $10.12681 /$ prch.28560

Copyright (C 2021, Michael Stork

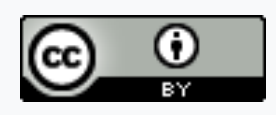

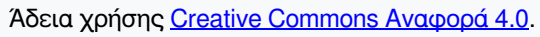

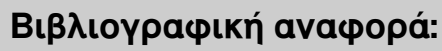

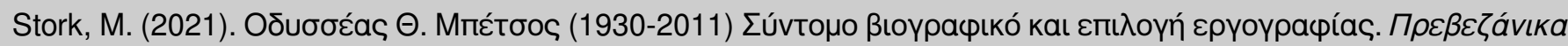
Xроvıкá, (47-48), 08-14. https://doi.org/10.12681/prch.28560 


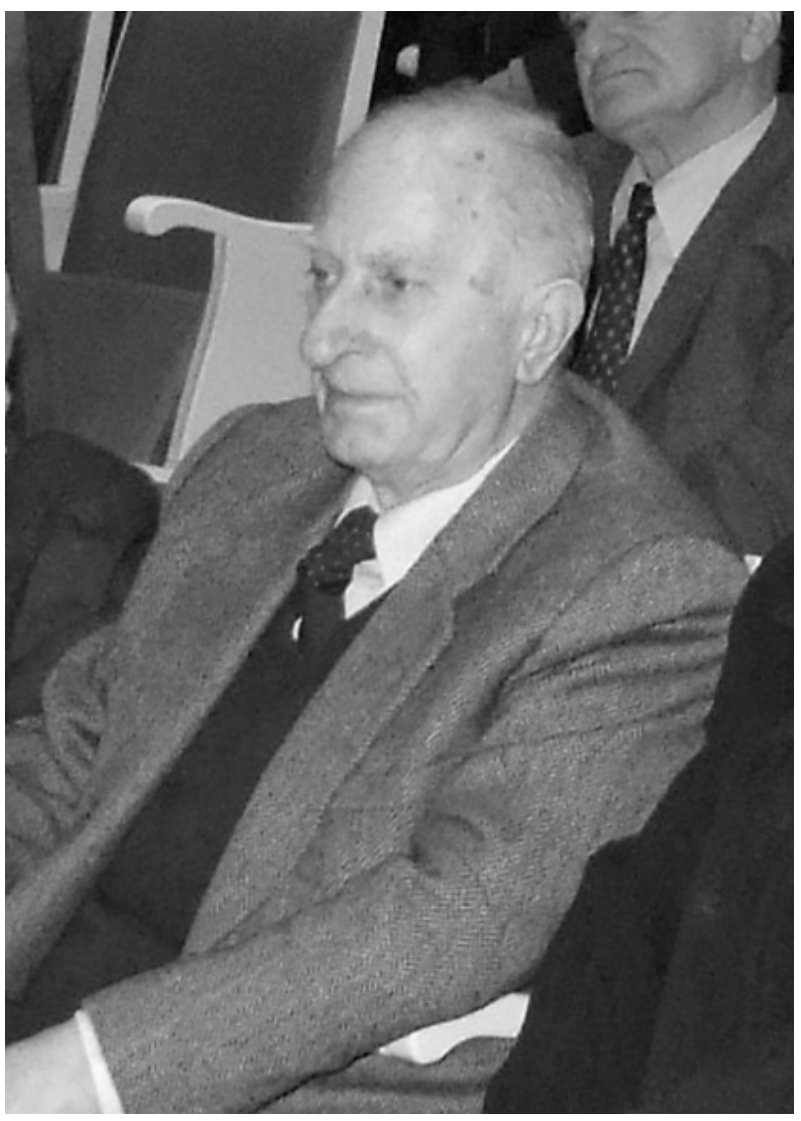

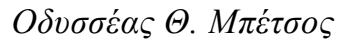

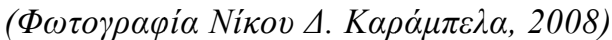




\title{
Michael STORK
}

\author{
$O \delta v \sigma \sigma \varepsilon \dot{\alpha} \Theta \Theta . M \pi \varepsilon ́ \tau \sigma o \varsigma(1930-2011)$

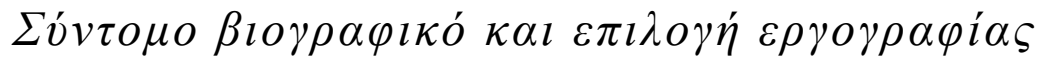

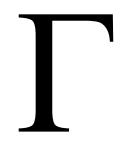

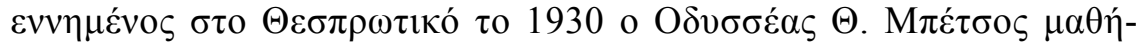

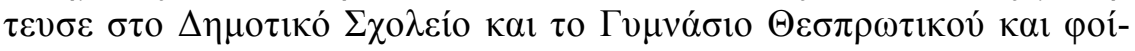

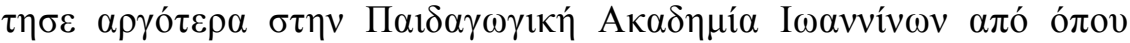

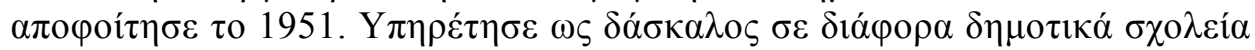

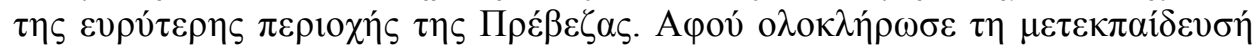

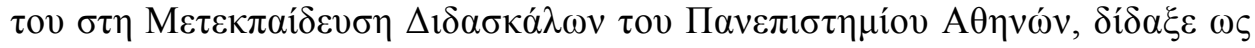

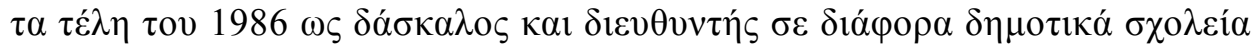

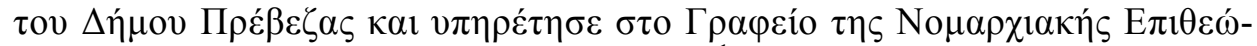

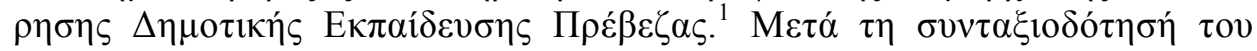

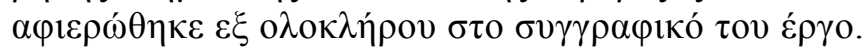

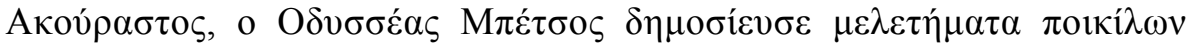

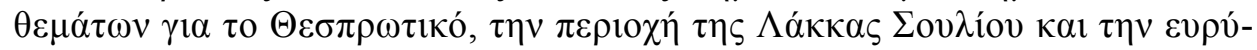

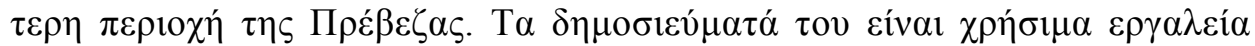

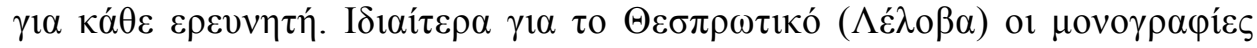

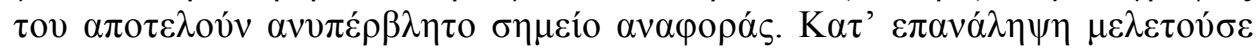

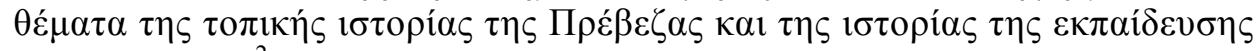

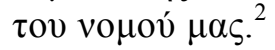

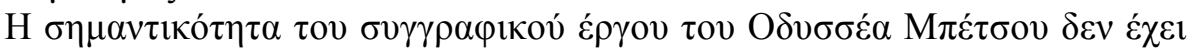

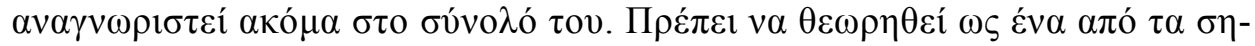

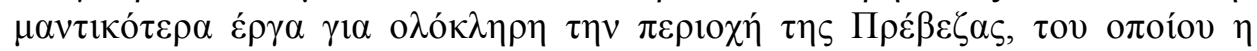

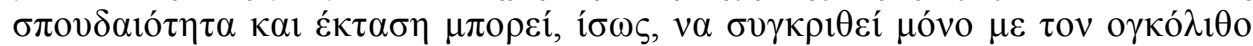

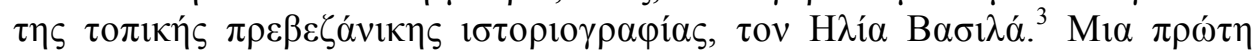

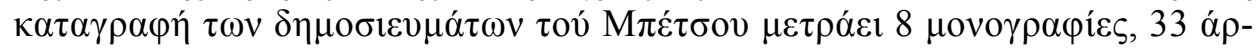

\footnotetext{
${ }^{1}$ MПEтгог 2006, 244· ПАПААHMHTPIOY 2011.

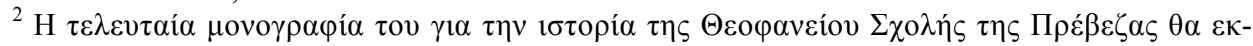

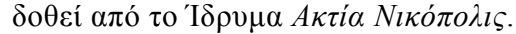

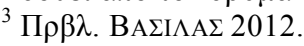




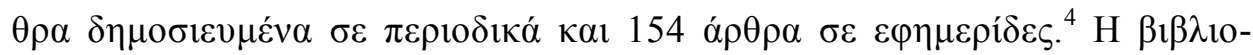

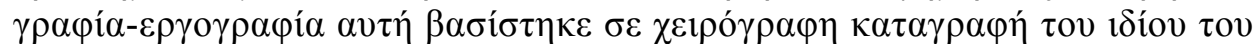

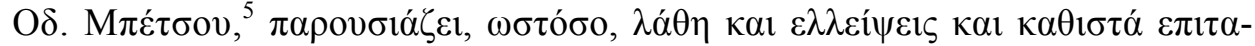

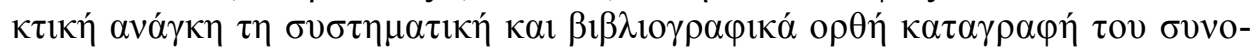

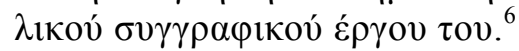

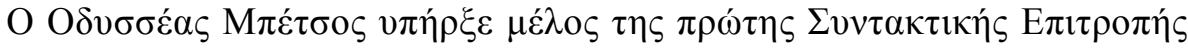

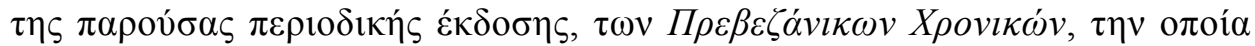

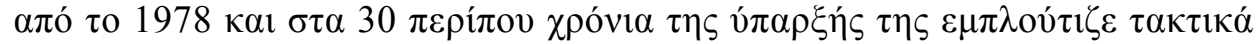

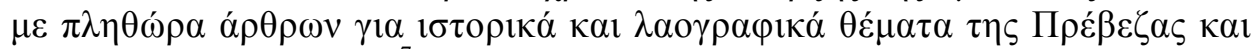

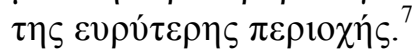

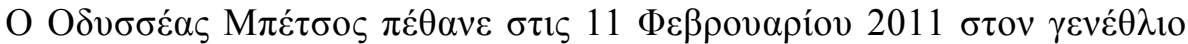

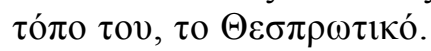

$\cos 80$

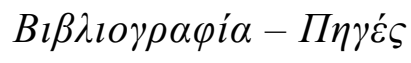

BA $\Sigma$ I $\Lambda$ A $\Sigma$ H.B., 2012, A $A \alpha \alpha \tau \tau \alpha, ~ П \rho \varepsilon ́ \beta \varepsilon \zeta \alpha$

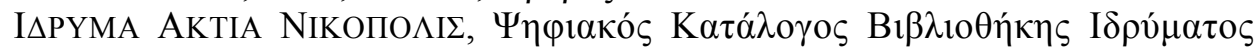

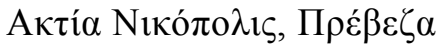

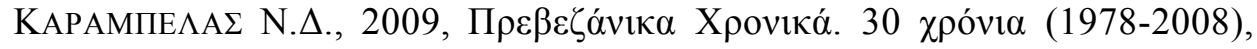

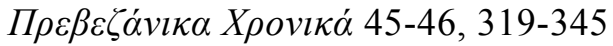

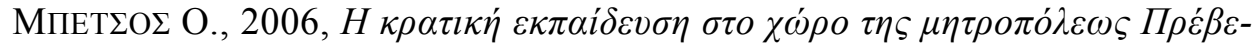

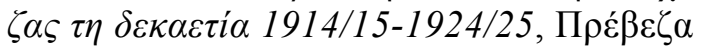

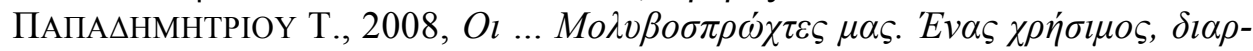

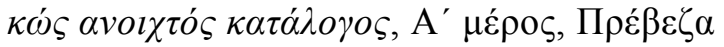

ПАПА

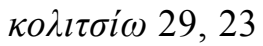

$\operatorname{sos}$

\footnotetext{
${ }^{4}$ ПАПА $\triangle$ HMHTPIOY 2008, 12-20.

${ }^{5}$ ПАПААНMHТPIOY 2008, 12.

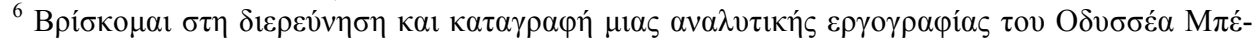

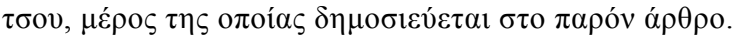

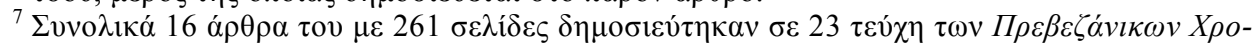

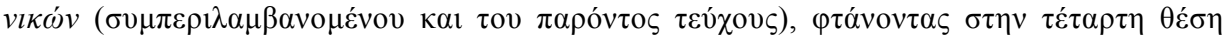

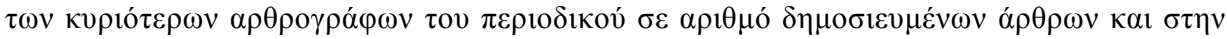

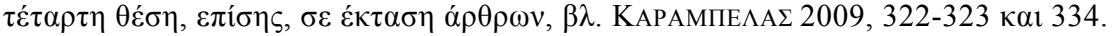




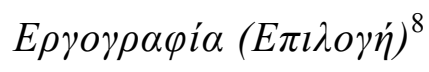

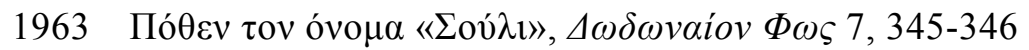

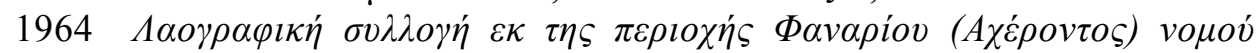

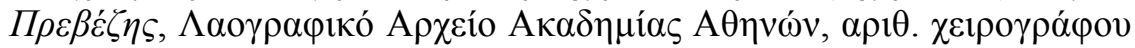

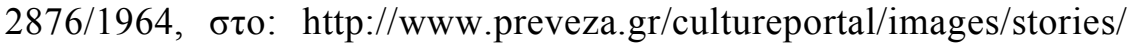
AKADIMIA_ATHINON/laogr_arxeio2876.pdf

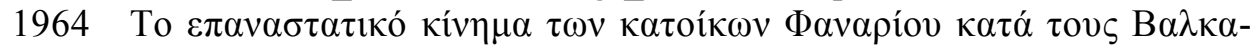

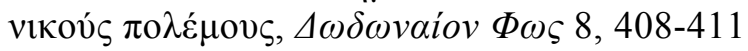

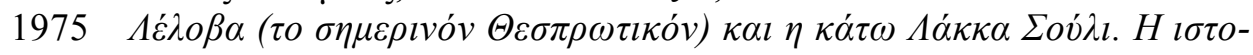

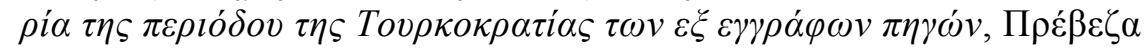

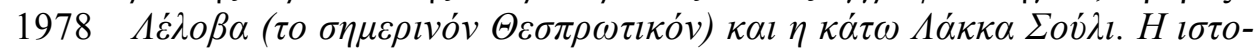

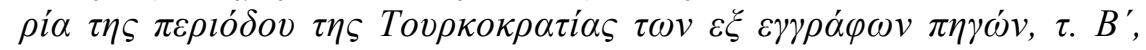

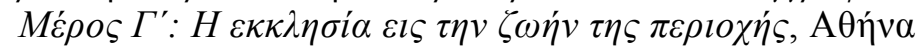

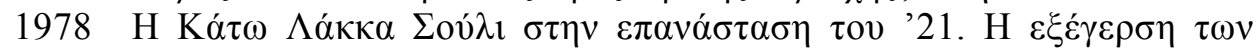

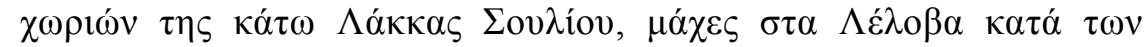

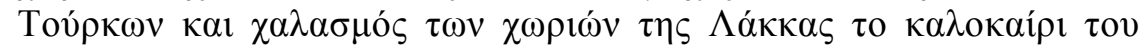

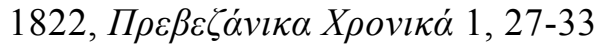

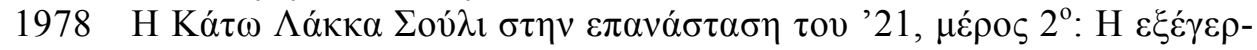

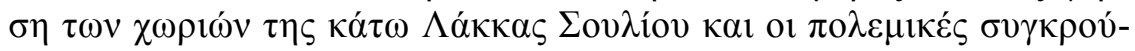

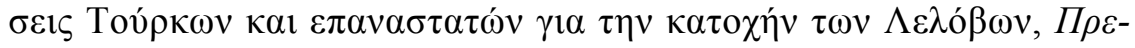

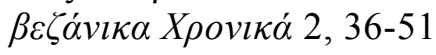

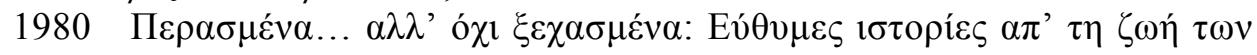

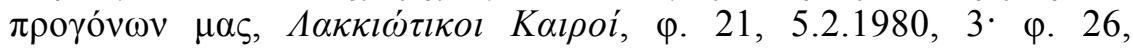

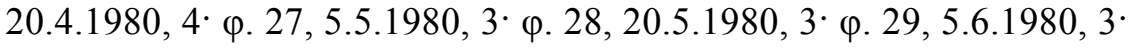
甲. 36, 20.9.1980, 3

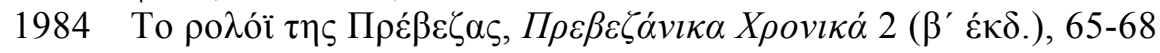

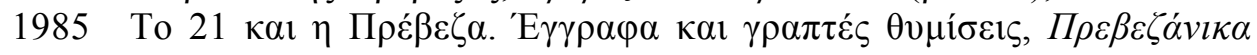
Хроvıко́ 5, 27-41

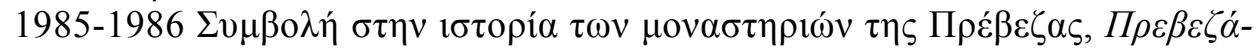

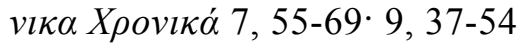

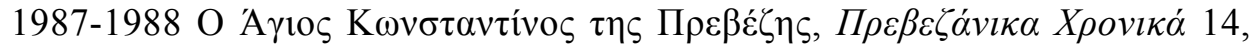
$48-53 \cdot 15,53-57 \cdot 16,47-60 \cdot 17,51-63 \cdot 18,53-64 \cdot 19-20,71-85$

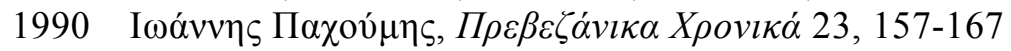

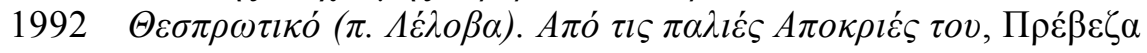

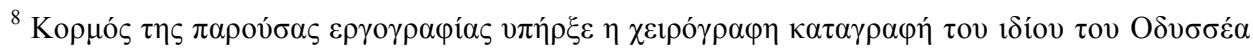

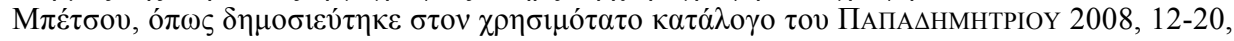

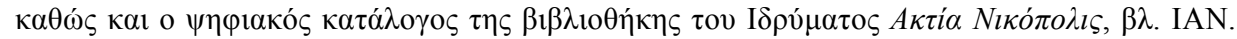

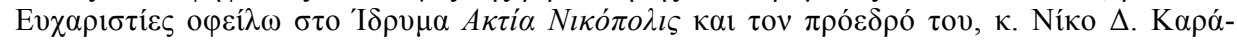

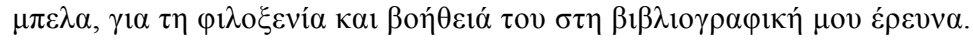




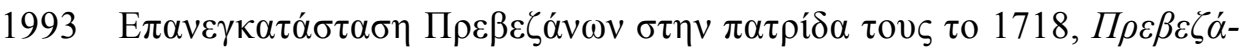

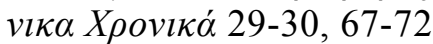

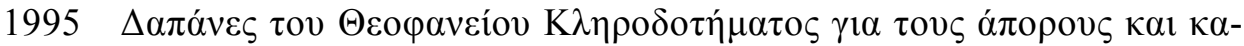

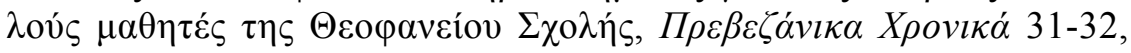
$33-43$

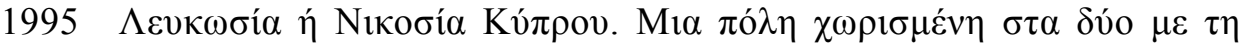

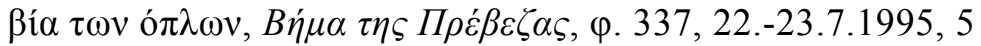

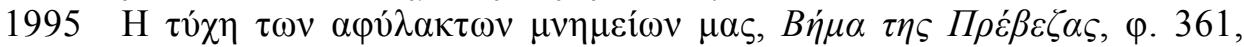
31.8.1995, 6

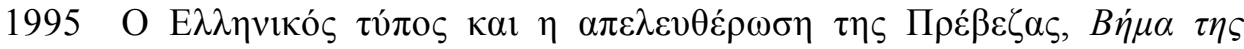
Прє́ं $\beta \varepsilon \zeta \alpha \varsigma, \varphi .397,20.10 .1995,1,5$

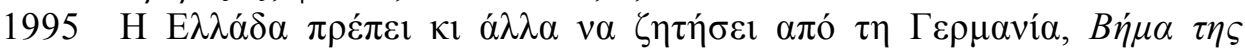
Прє́⿻ $\beta \varepsilon \zeta \alpha \varsigma, \varphi .429,5.12 .1995,5$

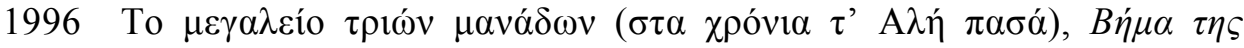

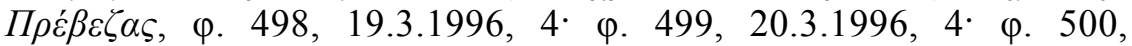
21.3.1996, 4· $\varphi .501,22.3 .1996,4$

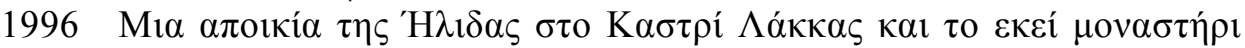

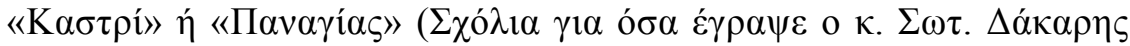

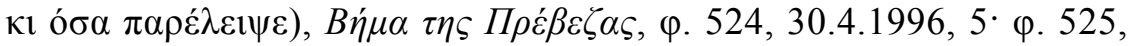
1.5.1996, 5· $\varphi .526,3.5 .1996,5 \cdot \varphi .527,4 .-5.5 .1996,4 \cdot \varphi .528$,

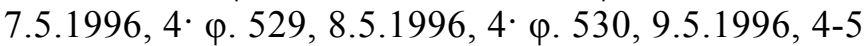

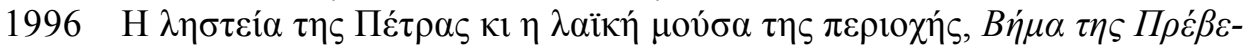
$\zeta \alpha \varsigma, \varphi .554,13.6 .1996,4 \cdot \varphi .555$. 14.6.1996, 4· $\varphi .556,15 .-16.6 .1996$, 4· $\varphi .557,18.6 .1996,4 \cdot \varphi .558,19.6 .1996,4$

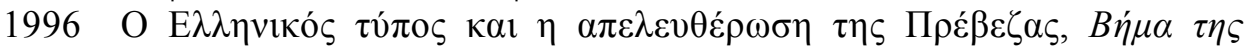

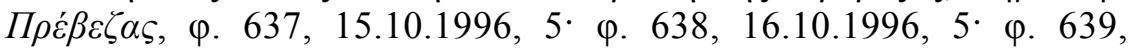
$17.10 .1996,5 \cdot \varphi .640,18.10 .1996,5$

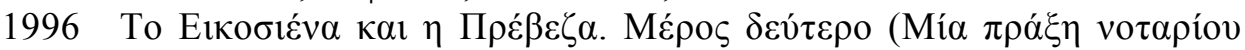

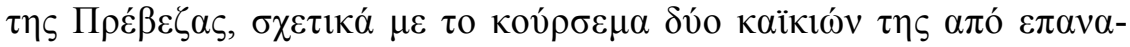

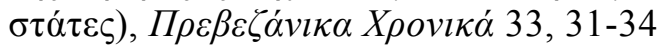

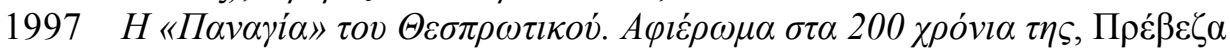

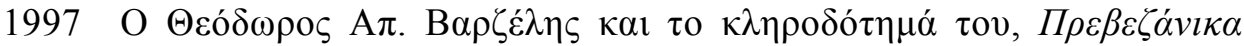
Хроvıка́ 34-35, 27-46

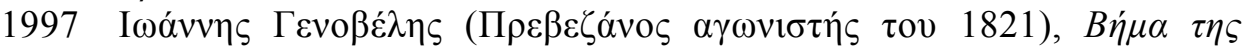
Прє́ं $\beta \varepsilon \zeta \alpha \varsigma, \varphi . ~ 742,25.3 .1997,4-5,7$

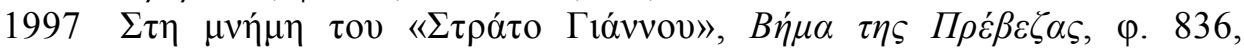
19.8.1997, 4· $\varphi .837,20.8 .1997,6 \cdot \varphi .838,21.8 .1997,4 \cdot \varphi .839$,

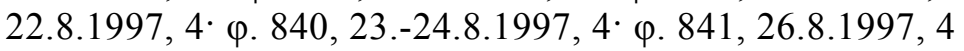

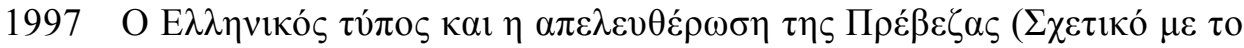

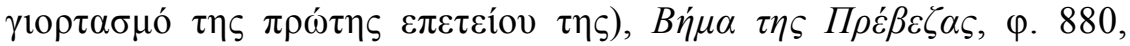
18.-19.10.1997, 4· $\varphi .881,21.10 .1997,4$ 


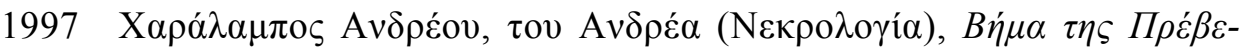
$\zeta \alpha \varsigma, \varphi .888,1 .-2.11 .1997,4-5$

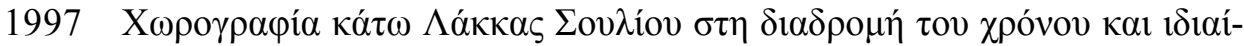
$\tau \varepsilon \rho \alpha$ tov $\lambda$ ó

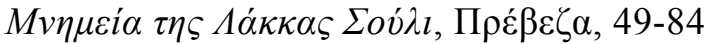

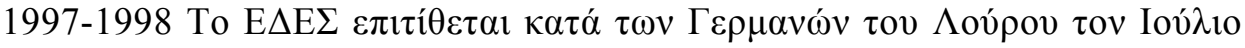

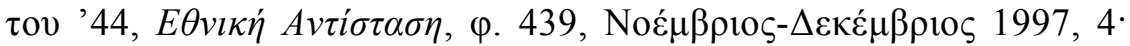

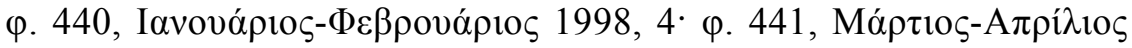
1998, 4

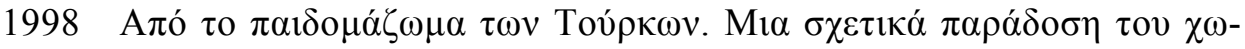

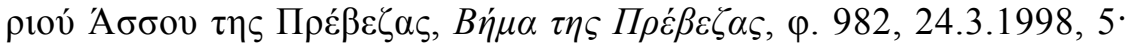
甲. 983, 25.3.1998, 5

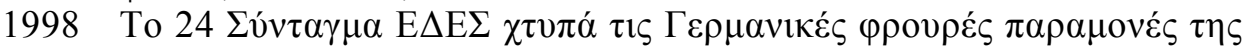

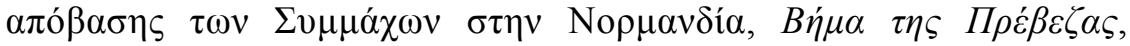

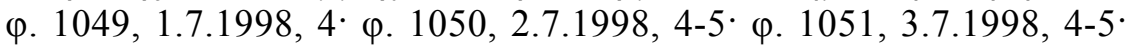

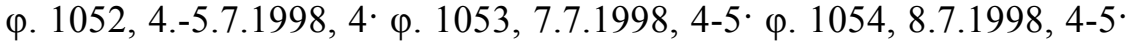
甲. $1055,9.7 .1998,4$

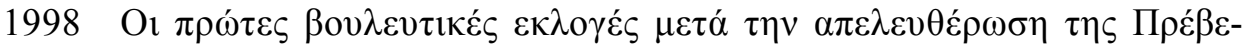

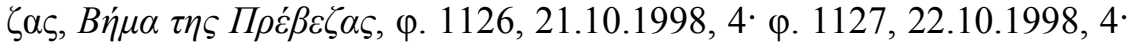

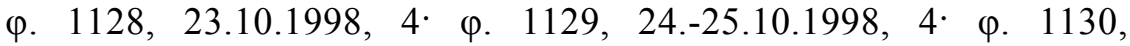
27.10.1998, 4· $\varphi .1131,28.10 .1998,4 \cdot \varphi .1132,30.10 .1998,4 \cdot \varphi$. 1133, 31.10.-1.11.1998, 4·

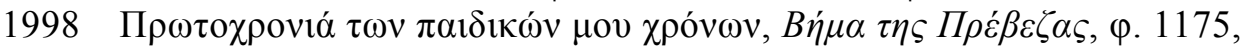
31.12.1998, 3-4, 14-16

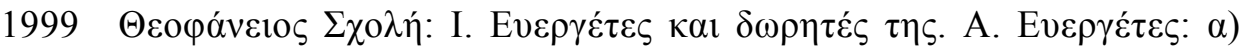

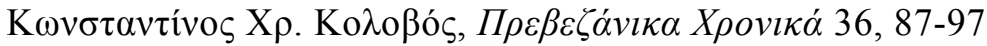

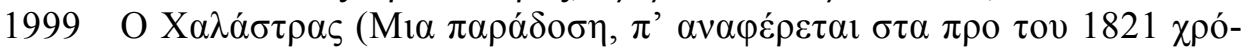

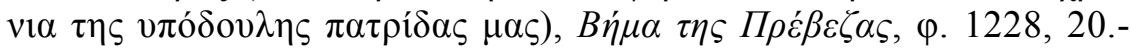
21.3.1999, 5· ம. 1229, 23.3.1999, 5·1230, 24.3.1999, 4

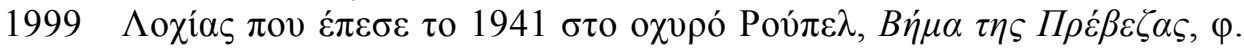
$1378,28.10 .1999,4,8$

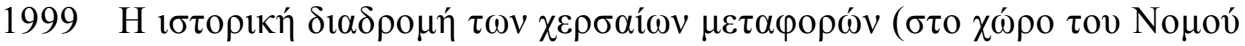

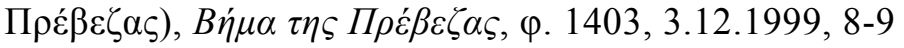

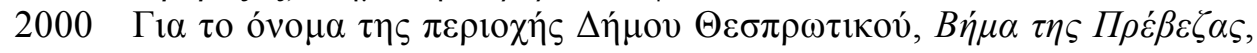
甲. 1495, 18.4.2000, 9

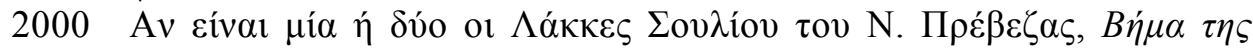

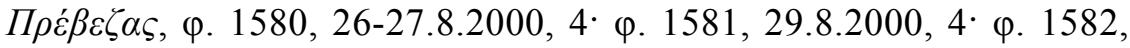
30.8.2000, 4· ต. 1583, 31.8.2000, 4

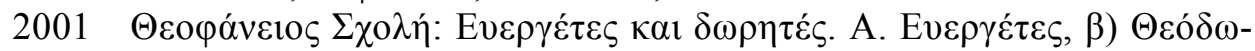

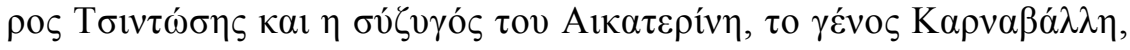

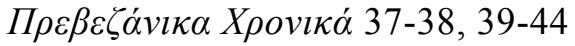




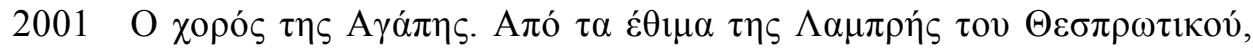

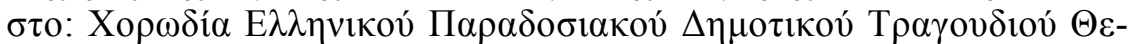

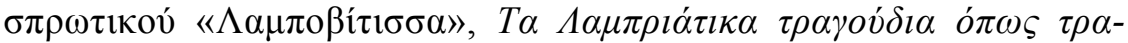

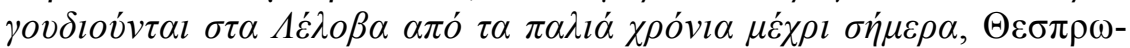

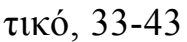

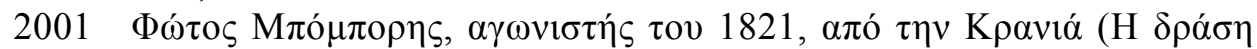

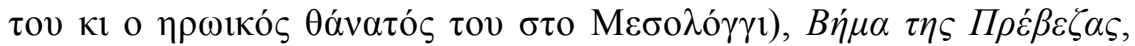
甲. 1722, 23.3.2001, 9· $\varphi .1723,24-25.3 .2001,9$

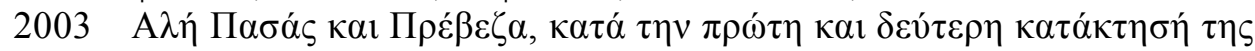

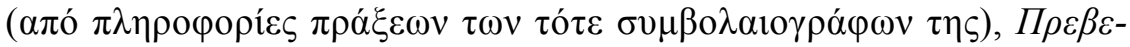

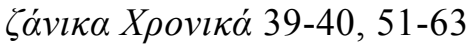

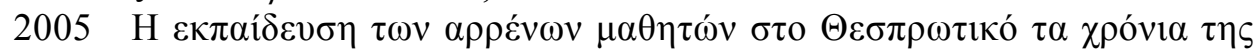

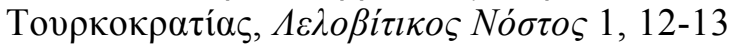

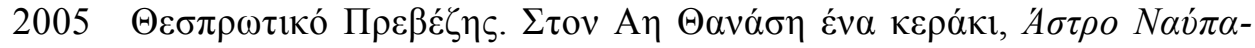

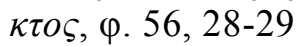

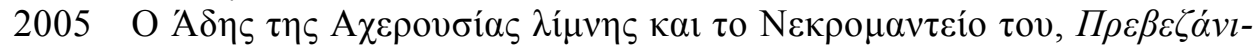

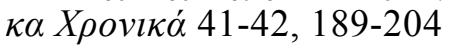

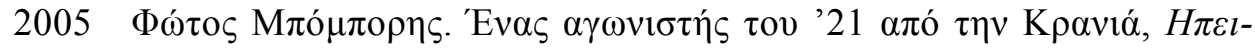
$\rho \omega \tau \omega ́ v$ Kolvóv 1, 111-118

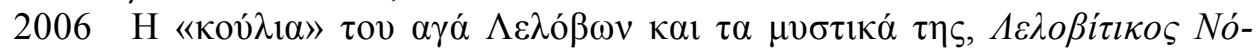
$\sigma \tau o \varsigma 4,12-13$

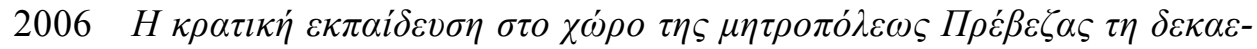

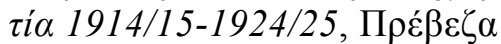

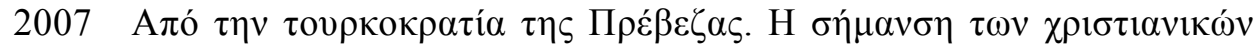

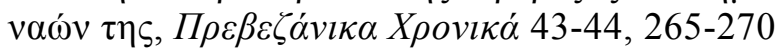

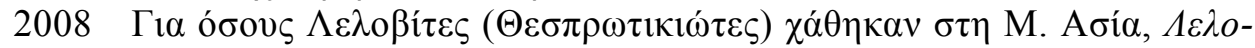

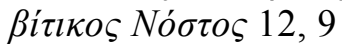

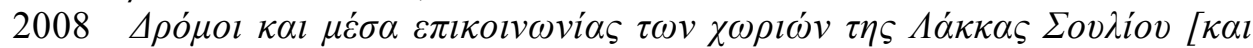

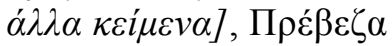

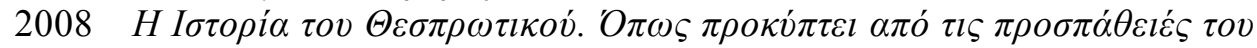

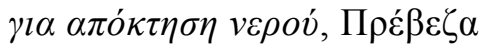

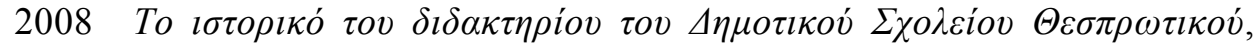
$\Pi \rho \varepsilon \dot{\beta \varepsilon} \zeta \alpha$

$2009 \Delta$ เód

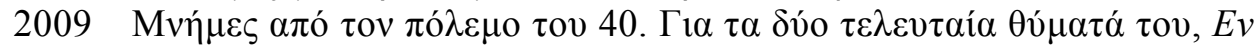

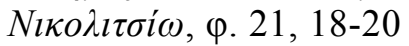

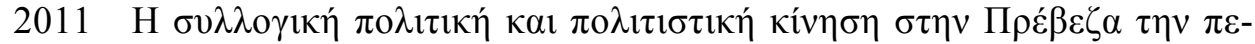

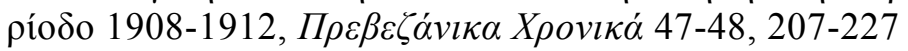

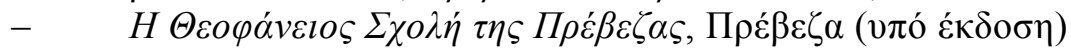

